\title{
Vasopressin and Catecholamine Secretion during Metabolic Acidemia in the Ovine Fetus ${ }^{1}$
}

\author{
DANIEL J. FAUCHER, THOMAS W. LOWE, RONALD R. MAGNESS, ABBOT R. LAPTOOK, \\ JOHN C. PORTER, AND CHARLES R. ROSENFELD \\ Departments of Pediatrics, Obstetrics and Gynecology and Physiology, The University of Texas, \\ Southwestern Medical School, Dallas, Texas 75235
}

\begin{abstract}
It has been suggested that the substantial rise in fetal plasma arginine vasopressin (AVP) during intrauterine hypoxia/asphyxia reflects decreases in $\mathbf{P a O}_{2}$ and/or pHa; however, the components of these "stresses," i.e. $\mathrm{PO}_{2}, \mathrm{PCO}_{2}$, and $\mathrm{pH}$, have not been controlled. Recently, only modest increases in fetal AVP secretion were seen during hypoxia independent of changes in $\mathrm{pH}$ and $\mathrm{PCO}_{2}$. Since the independent effects of metabolic acidosis on fetal AVP secretion are unknown, we induced acute metabolic acidemia in fetal sheep at $137 \pm 4$ (mean \pm SD) days gestation with $1 \mathrm{M} \mathrm{NH} \mathrm{NH}_{4}$, while monitoring mean arterial pressure, heart rate, $\mathrm{PaO}_{2}, \mathrm{PaCO}_{2}, \mathrm{pHa}$, plasma osmolality, and blood concentrations of electrolytes, AVP, dopamine, norepinephrine, and epinephrine. Mean arterial pressure, $\mathrm{PaO}_{2}, \mathrm{PaCO}_{2}$, and plasma osmolality and sodium were unchanged; pHa decreased from $7.37 \pm 0.01$ to 7.04 $\pm 0.05(p<0.05)$ during $\mathrm{NH}_{4} \mathrm{Cl}$ and did not return to control levels until 24 h later. AVP increased from $2.85 \pm$ 0.23 to $5.26 \pm 1.11 \mu \mathrm{U} / \mathrm{ml}(p<0.05)$ at the time of maximum acidosis, correlating with the fall in $\mathrm{pHa}(r=$ $\mathbf{- 0 . 6 7 , p}=0.001$ ); however, after stopping $\mathrm{NH}_{4} \mathrm{Cl}$, AVP returned to baseline levels although $\mathrm{pHa}$ remained $<7.15$. In control studies using the same osmolar load, volume, and rate of infusion, AVP levels were unchanged. Only epinephrine was significantly $(p<0.05)$ elevated during acidosis, but did not correlate with pHa or plasma AVP. Marked metabolic acidemia appears to have little or no effect on fetal AVP secretion, and fetal catecholamine secretion is variable. (Pediatr Res 21: 38-43, 1987)
\end{abstract}

\section{Abbreviations}

AVP, arginine vasopressin

DA, dopamine

NE, norepinephrine

E, epinephrine

MAP, mean arterial pressure

HR, heart rate

ANOVA, analysis of variance

Elevated plasma concentrations of AVP have been observed in adult animals during various forms of "stress" (1). Similarly, increased AVP levels have been reported in the umbilical cord

Reccived May 27, 1986; accepted August 12, 1986.

Address all correspondence to Charles R. Rosenfeld, M.D., Department of Pediatrics. The University of Texas Health Science Center at Dallas, 5323 Harry Hines Boulevard. Dallas, TX 75235.

Supported in part by NIH Grants HD-08783, HD-11149, and AM-01237 and a grant obtained from the Dallas Crystal Charity Ball.

' Presented in part at the 7th International Congress of Endocrinology, Quebec City. Canada, June 1984. plasma of human infants (2-5) and shown to reflect not only the route and "stresses" of delivery, but also the occurrence of additional intrauterine "stresses" $(2,5,6)$. Furthermore, elevated plasma levels of AVP are seen in fetal sheep during hemorrhage (7-9) and hypoxia/asphyxia (10-14). Thus it appears that, as in the adult, AVP may be considered a "stress" hormone in the fetus.

Whereas the stimulus for fetal hypersecretion of AVP during hemorrhage is clear, i.e. hypovolemia and baroreceptor mechanisms (9), the mechanisms(s) responsible for fetal AVP release during hypoxia/asphyxia is less clear. For example, although it has been suggested that during hypoxic insults $(11,13,15)$ and parturition (14) the fall in $\mathrm{PO}_{2}$ is responsible for the elevated plasma levels of AVP, neither pH nor $\mathrm{PCO}_{2}$ were controlled. Recently, we (12) reported that during mild to moderate fetal hypoxemia (a fall in $\mathrm{PaO}_{2}$ from 20 to $11 \mathrm{~mm} \mathrm{Hg}$ ) in the absence of alterations in either pHa or $\mathrm{PaCO}_{2}$, plasma AVP levels rose from 2 to $10 \mu \mathrm{U} / \mathrm{ml}(2.5 \mathrm{pg} / \mathrm{ml}=1.0 \mu \mathrm{U} / \mathrm{ml})$ in contrast to the substantially greater increases reported by others and the nearly 200 -fold rise observed during asphyxia, i.e. in the presence of hypoxemia, hypercapnia and acidosis (12). Moreover, we observed that maximum AVP levels were not reached until $30 \mathrm{~min}$ after the induction of hypoxemia, whereas maximum cardiovascular responses were seen within $5 \mathrm{~min}$. From these observations we hypothesized that hypoxemia, as an independent variable, acts only as a modest stimulant of fetal AVP release, and thus, might not account for the substantially greater increases in AVP previously reported, that AVP might not be the primary hormonal response to hypoxemia, and finally, that the rise in plasma AVP could not account for the immediate cardiovascular changes that were seen. Moreover, it appeared that the role of $\mathrm{PCO}_{2}$ and $\mathrm{pH}$ in fetal AVP release remained to be determined.

Catecholamines also are released during various "stress" states (16), e.g. plasma E concentrations increase 20 -fold during the first $5 \mathrm{~min}$ after induction of hypoxemia in fetal sheep (17). However, in contrast to that seen with AVP, the rise in plasma catecholamines appears to coincide with the cardiovascular alterations (17). Therefore, an interaction may exist between neurotransmitters, such as catecholamines, and the magnocellular system (1).

Inasmuch as the mechanism(s) responsible for the hypersecretion of AVP and its relationship with catecholamine secretion is unclear, we sought to ascertain in the present investigation the effects of pure metabolic acidemia on fetal secretion of this peptide hormone, and the relationship that might exist between AVP and the changes in plasma levels of DA, NE, and E.

\section{MATERIALS AND METHODS}

Animal preparation. Six ewes of mixed Western breed bearing singleton fetuses were used to study the effects of $\mathrm{NH}_{4} \mathrm{Cl}$ infusion. Surgery and studies were performed at $126 \pm 2.1(\mathrm{SD})$ and 137 
\pm 4.3 days of gestation (term $\sim 145$ days), respectively. The surgical procedure for the preparation of the chronically instrumented sheep model has been previously described in detail (18, 19). In brief, after sedation with intravenous ketamine hydrochloride $(2 \mathrm{mg} / \mathrm{kg})$, spinal anesthesia was induced with hyperbaric pontocaine hydrochloride $(12 \mathrm{mg}$ ) and supplemented with intravenous sodium pentobarbital as needed $(15 \mathrm{mg} / \mathrm{kg})$. The uterus was exposed through a midline abdominal incision, withdrawn from the abdominal cavity, and wrapped in warm, moist towels. One fetal hindlimb was brought out through a small uterine incision, and polyvinyl catheters were inserted into the femoral artery (the tip lying in the lower aorta) and the femoral vein (the tip lying in the high vena cava). Another catheter was placed in the amniotic sac near the external meatus of the fetal urethra. Ampicillin ( $250 \mathrm{mg}$ ) was instilled in the amniotic cavity. The uterine incision was closed, and the uterus was replaced in the abdominal cavity of the ewe.

Electromagnetic flow probes (Micron Instruments, Los Angeles, CA) of appropriate internal diameter were implanted around both main uterine arteries proximal to their bifurcation, enabling us to measure blood flow continuously during the experimental protocol. All intraabdominal catheters and the flow probe leads were brought out of the abdomen through a stab wound in the fascia, and the abdomen was closed. Through a separate inguinal incision a catheter was inserted into the maternal femoral artery (the tip lying just distal to the aortic bifurcation) and another into the maternal femoral vein (the tip lying just below the diaphragm in the inferior vena cava). All catheters and flow probe leads were brought out to the flank through a subcutaneous tunnel and placed in a canvas pouch that was attached to the skin with steel pins. The animal was then returned to the laboratory and provided feed ad libitum (Purina Commercial Creep Chow II, G, St. Louis, MO). The catheters were flushed daily with $0.15 \mathrm{M} \mathrm{NaCl}$ containing heparin $(250 \mathrm{U} / \mathrm{ml})$ and sealed with sterile metal pins. The ewes were given penicillin $\mathrm{G}(600,000$ $\mathrm{U})$ and streptomycin $(0.5 \mathrm{~g})$ on the day of surgery and for the next 2 postoperative days. The fetuses were given ampicillin (50 $\mathrm{mg}$ ) into the amniotic sac every other day. Each animal was allowed to recover from surgery and anesthesia for at least 6 days before studies were initiated. Fetal sheep with abnormal blood gases or $\mathrm{pH}$ were not studied.

Experimental protocol. Ammonium chloride $\left(\mathrm{NH}_{4} \mathrm{Cl}\right)$ was prepared under aseptic conditions immediately before each experiment. Six animals were used in nine different experiments; all were infused with $1 \mathrm{M} \mathrm{NH} \mathrm{Nl}_{4} \mathrm{Cl}$ through the fetal femoral venous catheter. The length of infusion was $120 \mathrm{~min}$ or a time necessary to reach an arterial $\mathrm{pH}$ of $\sim 7.10$; two preparations were infused $80 \mathrm{~min}$, one $100 \mathrm{~min}$, and six $120 \mathrm{~min}$. All animals were infused at a rate of $0.382 \mathrm{ml} / \mathrm{min}$, or 0.03 to $0.07 \mathrm{mEq} / \mathrm{min} \cdot \mathrm{kg}$; fetal weight at the time of study was estimated at birth or sacrifice by the method of Gresham et al. (20). Control experiments were performed in five additional animals by infusing either saline $(n$ $=4$ ) or glucose $(n=5)$ in the same concentration, volume, and rate as with $\mathrm{NH}_{4} \mathrm{Cl}$. Animals were allowed to rest a minimum of 3 days between experiments.

MAP in the lower abdominal aorta of the ewe and fetus was continuously monitored using pressure transducers (type 4-3270109, Bell and Howell, Pasadena, CA) and the output was recorded by means of a two-channel pen-recorder (model 220, Brush Instruments, Div. Clevite Corp., Cleveland, OH). HR was obtained at intervals from a direct recording of the phasic signal from the arterial catheter. Uterine blood flow was monitored continuously with square-wave electromagnetic flowmeters (model RC-1000, Micron Instruments) and recorded on a second two-channel pen-recorder electronically integrated with the former.

Heparinized blood for the measurement of plasma AVP $(2.0$ $\mathrm{ml}$ ) and catecholamines $(1.0 \mathrm{ml})$ was obtained from the fetal femoral artery catheter before starting the infusion of $\mathrm{NH}_{4} \mathrm{Cl}$, at 20 -min intervals during the infusion, and at 30,60,90, 120, 150,
$180 \mathrm{~min}$, and 4, 8, and $24 \mathrm{~h}$ after the infusion was stopped. Arterial blood was obtained for blood gas analysis at similar times. Maternal blood was obtained from the femoral artery catheter for blood gas analysis before the infusion, at $80 \mathrm{~min}$ after the beginning of the infusion, and 1,4 , and $24 \mathrm{~h}$ after completing the infusion. Each sample of blood collected for AVP and catecholamines was centrifuged immediately, the plasma removed, the erythrocytes resuspended in a volume of sterile isotonic saline equal to the plasma volume, and reinfused into the fetus in the manner previously reported (19).

Samples of amniotic fluid $(2 \mathrm{ml})$ were collected before starting the $\mathrm{NH}_{4} \mathrm{Cl}$ infusion, at 20 and 60 min during the infusion, at the end of the infusion, and $1,2,3,8$, and $24 \mathrm{~h}$ after stopping the infusion in five experiments.

Assays. Arterial blood samples $(0.5 \mathrm{ml}$ from the fetus and 0.8 $\mathrm{ml}$ from the ewe) for blood gas and $\mathrm{pH}$ determinations were collected in $1.0-\mathrm{ml}$ heparinized glass syringes and kept on ice until analyzed using a $\mathrm{pH} /$ gas analyzer (model 113, Instrumentation Laboratory, Lexington, MA). The hematocrit was measured on these samples by the micromethod of Wintrobe. Osmolality of fetal plasma was measured with an automatic osmometer (Osmette A, model 5002, Precision Systems, Sudbury, MA). Fetal plasma concentrations of sodium and potassium were determined by flame photometry using lithium as an internal standard (IL 443 flame photometer).

Blood samples for measurement of AVP were collected in chilled heparinized syringes and immediately transferred to sterile plastic centrifuge tubes. After centrifugation at $10,000 \times g$ for $60 \mathrm{~s}$ in a Beckman Microfuge, the plasma was removed, and a $1.0-\mathrm{ml}$ aliquot of the plasma was mixed with $2.0 \mathrm{ml}$ of cold acetone (for amniotic fluid, $1.0 \mathrm{ml}$ was mixed with $2.0 \mathrm{ml}$ of cold acetone). The acetone mixture, in which we have found AVP to be stable for at least $4 \mathrm{wk}$, was immediately placed on dry ice and later stored at $-20^{\circ} \mathrm{C}$. At the time of assay the plasma-acetone or amniotic fluid-acetone mixture was centrifuged at $3000 \times g$ for 2 min to sediment the denatured proteins. The supernatant fluid was removed and extracted with diethyl ether with a modification of the procedure of Robertson et al. (21). The aqueous phase was evaporated to dryness under a stream of nitrogen. The residue was suspended in $400 \mu \mathrm{l}$ of 0.15

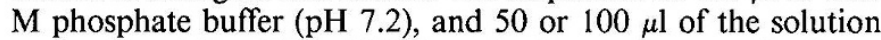
were assayed for AVP. AVP in extracts was measured using a radioimmunoassay procedure described by Skowsky et al. (22), as modified by Weitzman et al. (23). The use of this assay in our laboratory has been described and validated by DeVane and associates $(5,12)$. The sensitivity is $0.8 \mu \mathrm{U} / \mathrm{ml}$; the inter- and intra-assay variability are 7.9 and $8.9 \%$, respectively. The mean recovery of AVP from sheep plasma was $65-70 \%$. The data presented have not been corrected for recovery.

Blood samples for measurement of catecholamines were centrifuged at $10,000 \times g$ for $1 \mathrm{~min}$ and the fetal plasma mixed with an equal volume of $0.6 \mathrm{M}$ perchloric acid containing $0.1 \%$ EDTA. The supernate was stored at $-20^{\circ} \mathrm{C}$ until the time of assay for measurement of DA, NE, and $\mathrm{E}$. The catecholamines were quantified using the method of Ben-Jonathan and Porter (24). The assay is linear from 0 to $5 \mu \mathrm{g}$ for each catecholamine and has a sensitivity of $10-30 \mathrm{pg}$.

Data analysis. Repeated measures ANOVA was used to analyze changes over time; where significance was observed $(p<$ $0.05)$, this was further analyzed by Duncan's multiple range test for each variable and/or Student's paired $t$ test. Regressions lines were obtained by the least-squares method. Data are presented as the mean and 1 SE unless otherwise specified.

\section{RESULTS}

Baseline data for fetal and maternal arterial blood gases, hematocrit, HR, MAP, and uterine blood flow are presented in Table 1. Maternal heart rate, MAP, uterine blood flow, and arterial blood gases were unchanged during the fetal infusion of $\mathrm{NH}_{4} \mathrm{Cl}$. 
Table 1. Baseline maternal and fetal arterial blood gases and hemodynamic variables (mean $\pm S E$ )

\begin{tabular}{lcc}
\hline & Maternal & Fetal \\
\hline Arterial blood gases & & \\
$\mathrm{PO}_{2}(\mathrm{~mm} \mathrm{Hg})$ & $103 \pm 2.2$ & $18.5 \pm 0.5$ \\
$\mathrm{PCO}_{2}(\mathrm{~mm} \mathrm{Hg})$ & $29 \pm 0.7$ & $44.8 \pm 2.0$ \\
$\mathrm{pH}$ & $7.50 \pm 0.02$ & $7.37 \pm 0.01$ \\
Base deficit & $+1.6 \pm 1.3$ & $+0.1 \pm 1.2$ \\
Hematocrit & $28 \pm 1.5$ & $37 \pm 2.4$ \\
Heart rate (beat/min) & $105 \pm 7.4$ & $154 \pm 5.8$ \\
Mean arterial pressure $(\mathrm{mm} \mathrm{Hg})$ & $84 \pm 2.3$ & $51 \pm 1.9$ \\
Total uterine blood flow $(\mathrm{ml} / \mathrm{min})$ & $761 \pm 86.0$ & \\
\hline
\end{tabular}

As illustrated in Figure 1, the fetal arterial pH significantly decreased during the infusion of $\mathrm{NH}_{4} \mathrm{Cl}$, gradually falling to 7.04 \pm 0.05 by $120 \mathrm{~min}(p<0.05)$. After the $\mathrm{NH}_{4} \mathrm{Cl}$ infusion, $\mathrm{pHa}$ rose quite slowly, reaching a value of only $7.24 \pm 0.03$ by $8 \mathrm{~h}$ postinfusion; at $24 \mathrm{~h}$ postinfusion, the pHa was not significantly different from control. The fall in $\mathrm{pHa}$ at $120 \mathrm{~min}$ was associated with a base deficit of $-19 \pm 2.1(p<0.05)$. Although fetal $\mathrm{PaO}_{2}$ rose during the development of acidemia (Figure 2) and remained $\sim 12 \%$ above control values during the $\mathrm{NH}_{4} \mathrm{Cl}$ infusion, this increase did not achieve statistical significance. However, this rise in $\mathrm{PaO}_{2}$ correlated, although weakly, with the fall in $\mathrm{pHa}(r$ $=-0.294, n=45, p<0.05$ ). Neither the fetal $\mathrm{PaCO}_{2}$ nor the hematocrit were significantly changed during and after the $\mathrm{NH}_{4} \mathrm{Cl}$ infusion.

Serial measurements of fetal plasma osmolality were obtained in seven experiments. We did not observe any change in plasma osmolality over the entire experimental protocol; values before and at $120 \mathrm{~min}$ of the $\mathrm{NH}_{4} \mathrm{Cl}$ infusion were $269 \pm 5$ and $272 \pm$ $4 \mathrm{mosmol} / \mathrm{kg} \mathrm{H}_{2} \mathrm{O}$, respectively.

Although the plasma concentration of sodium did not change, the mean plasma potassium concentration increased from 3.45 \pm 0.14 to $4.24 \pm 0.14 \mathrm{mEq} /$ liter $(p<0.05)$ by the end of the infusion and gradually decreased thereafter, reaching a value of $3.69 \pm 0.23 \mathrm{mEq} / \mathrm{liter}$ by $24 \mathrm{~h}$ postinfusion.

As illustrated in Figure 1, despite the development of rather marked metabolic acidemia, plasma concentrations of AVP increased gradually from $2.85 \pm 0.23$ to $5.26 \pm 1.11 \mu \mathrm{U} / \mathrm{ml}$ at 120 min. After the $\mathrm{NH}_{4} \mathrm{Cl}$ infusion plasma concentrations of AVP fell rapidly even though significant metabolic acidemia persisted, reaching a value of $3.16 \pm 0.93 \mu \mathrm{U} / \mathrm{ml}$ within $60 \mathrm{~min}$, a value not different from control $(p>0.05)$. Nevertheless, the relationship between the fall in pHa and rise in plasma AVP during the $\mathrm{NH}_{4} \mathrm{Cl}$ infusion was highly significant $(r=-0.671, p=0.001, n$ $=38$ ). Because the rise in plasma AVP may have been reflective of the osmolality of the infusate $\left(2000 \mathrm{mosmol} / \mathrm{kg} \mathrm{H}_{2} \mathrm{O}\right)$, we performed control studies, infusing sodium chloride $(n=4)$ or glucose $(n=5)$ at the same rate, volume, and molar concentrations. In these studies, plasma concentrations of AVP were unchanged with both infusates: at control, AVP was $1.61 \pm 0.16$ and $1.49 \pm 0.17 \mu \mathrm{U} / \mathrm{ml}$ for sodium chloride and glucose, respectively, and at $120 \mathrm{~min}$ of infusion values were $1.99 \pm 0.51$ and $1.42 \pm 0.12 \mu \mathrm{U} / \mathrm{ml}(p>0.1)$, respectively. As with $\mathrm{NH}_{4} \mathrm{Cl}$, there was no significant change in plasma osmolality.

The patterns of change in plasma concentrations of catecholamines before, during, and after the infusion of $\mathrm{NH}_{4} \mathrm{Cl}$ are presented in Figure 3. Although plasma concentrations of DA, $\mathrm{NE}$, and $\mathrm{E}$ gradually rose during the development of metabolic acidosis, these changes were not statistically significant (ANOVA) because of the large variability in the response of different animals. When this variability was taken into account by log transformation of the plasma concentrations, significant increases in only E were observed at 60,80 , and $120 \mathrm{~min}$ after beginning the $\mathrm{NH}_{4} \mathrm{Cl}$ infusion. There were no significant correlations between the changes in $\mathrm{pHa}$ or plasma levels of AVP with either DA, NE, or $\mathrm{E}$ during the $\mathrm{NH}_{4} \mathrm{Cl}$ infusion.

The fetal cardiovascular responses to metabolic acidemia are

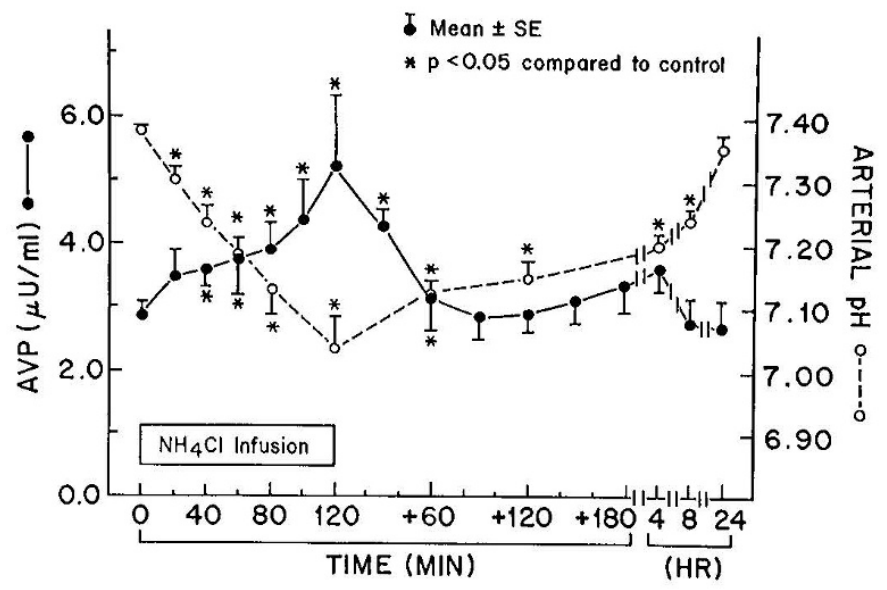

Fig. 1. The effect of $\mathrm{NH}_{4} \mathrm{Cl}$ infusion $(120 \mathrm{~min})$ on fetal arterial $\mathrm{pH}$ and plasma concentrations of AVP.

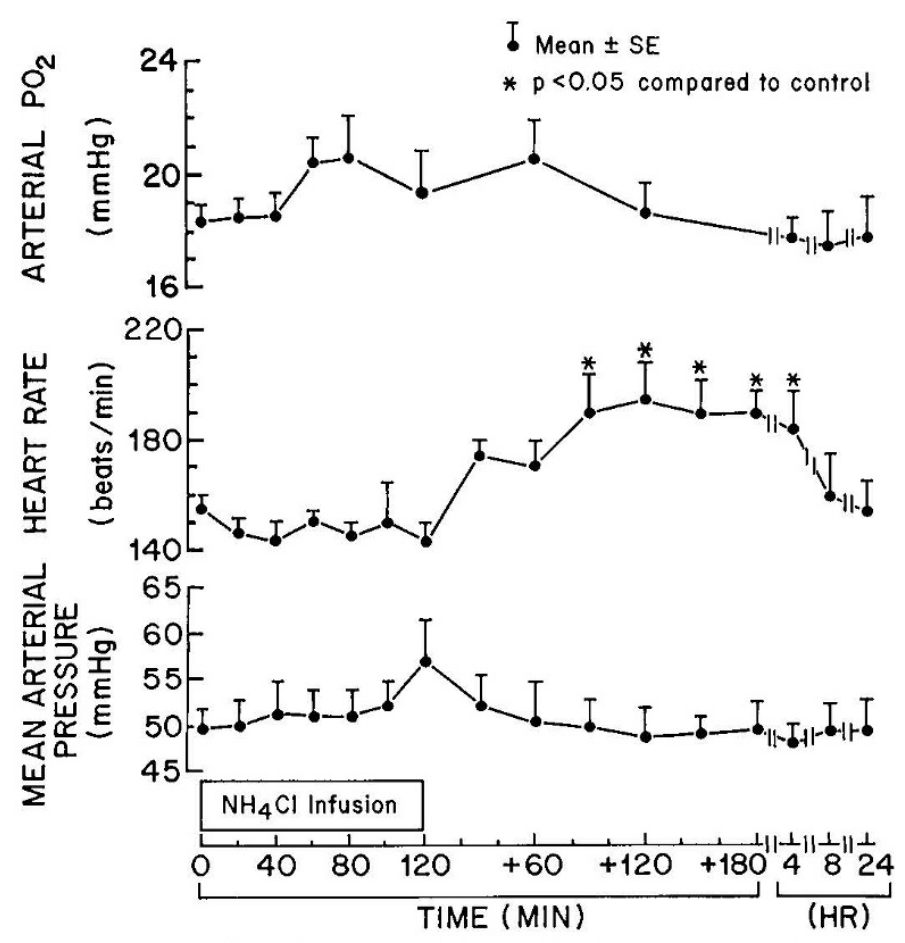

Fig. 2. The effect of $\mathrm{NH}_{4} \mathrm{Cl}$ infusion $\left(120 \mathrm{~min}\right.$ ) on fetal arterial $\mathrm{PO}_{2}$, $\mathrm{HR}$, and MAP.

shown in Figure 2. Fetal MAP was not significantly changed during or after the $\mathrm{NH}_{4} \mathrm{Cl}$ infusion. There was a slight fall in fetal $\mathrm{HR}$ of approximately 10 beats/min during the $\mathrm{NH}_{4} \mathrm{Cl}$ infusion; however, this was not significant. Following the $\mathrm{NH}_{4} \mathrm{Cl}$ infusion, a profound increase in $\mathrm{HR}$ was observed within $30 \mathrm{~min}$ after completion of the infusion, and HR remained significantly elevated until $4 \mathrm{~h}$ postinfusion. During this prolonged period of fetal tachycardia, metabolic acidemia persisted, plasma AVP and E concentrations returned to values not different from control, and $\mathrm{PaO}_{2}$ remained elevated. Although the plasma level of $\mathrm{NE}$ was not significantly elevated in the postinfusion period, the mean values remained above the preinfusion mean value. At 8 $\mathrm{h}$ postinfusion the HR had fallen to $162 \pm 15$ beat $/ \mathrm{min}$, a value not different from the control.

Amniotic fluid concentrations of AVP and catecholamines were measured serially in five experiments (Table 2 ). There were no significant changes in the concentrations of these hormones either during or after the $\mathrm{NH}_{4} \mathrm{Cl}$ infusion. Furthermore, there was no evidence of meconium release by the fetus into the 


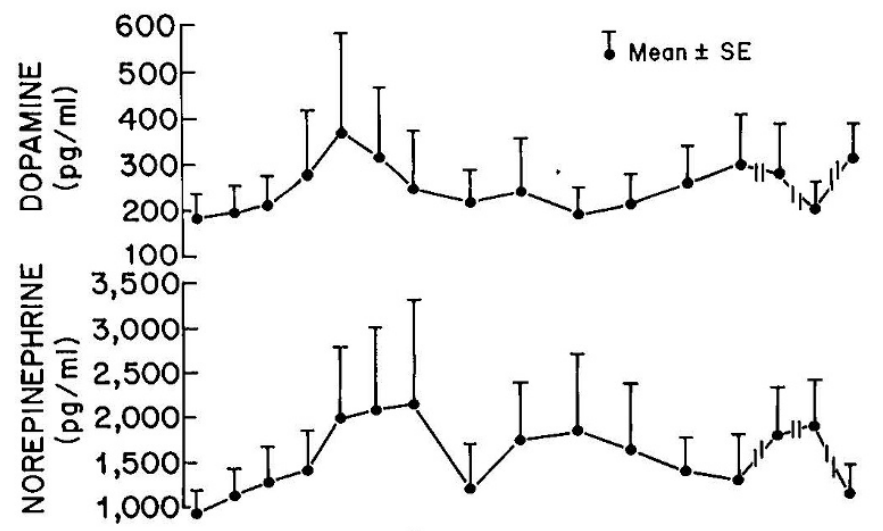

thermore, since different methods have been used to alter fetal oxygenation, e.g. reduced maternal inspired oxygen (15) and cord compression (11), reported concentrations of fetal plasma AVP have differed substantially, thereby making it difficult to ascertain whether the fall in fetal $\mathrm{PO}_{2}$ or $\mathrm{pH}$ or the rise in $\mathrm{PCO}_{2}$ is primarily responsible for the observed increases in plasma AVP, or whether this reflects changes in cardiac return due to cord compression. We further demonstrated the complexity of this problem when we observed a 200 -fold rise in plasma AVP levels during the simultaneous occurrence of hypoxemia, metabolic acidosis, and hypercapnia (i.e. asphyxia), but only a modest increase in the presence of hypoxemia (arterial oxygen tensions as low as $9 \mathrm{~mm} \mathrm{Hg}$ ) independent of changes in either $\mathrm{pHa}$ or $\mathrm{PaCO}_{2}$ (12). Since this was suggestive that hypoxemia alone had only modest effects on fetal neurohypophyseal release of AVP, and since the effects of metabolic acidosis alone were not known, we sought to ascertain in the present studies the role of metabolic acidemia in the release of this peptide hormone. Furthermore, since the magnocellular system undergoes important developmental changes during the perinatal period in several species (27), it seemed reasonable that similar maturational changes might occur in fetal sheep. Therefore, we have studied a small window of development, 130 to 140 days, in order to reduce the potential significance of this and other maturational variables.

In the present studies, the $\mathrm{NH}_{4} \mathrm{Cl}$-induced metabolic acidemia had only a very slight effect on fetal AVP release, a 2-fold rise, when compared to that seen in animals with either hypoxemia (4-fold) or asphyxia ( 200-fold) studied at a similar time in gestation (12). Although the $\mathrm{NH}_{4} \mathrm{Cl}$ solution infused was of relatively high osmolality, $2000 \mathrm{mosmol} / \mathrm{kg} \mathrm{H}_{2} \mathrm{O}$, we were able to demonstrate in control studies that neither the osmolar load nor the infused volume were responsible for the increase in plasma AVP levels. Furthermore, in none of these studies did we observe a change in plasma osmolality, sodium concentration, or hematocrit during the infusion of any of these substances. Thus, it is more likely that the rise in plasma AVP concentration may have resulted from the fall in arterial $\mathrm{pH}$ or was a direct effect of $\mathrm{NH}_{4} \mathrm{Cl}$ on the magnocellular system and/or the posterior pituitary gland. Of interest, there was a significant rise and fall in the plasma levels of potassium that were mirror images of the changes in arterial pH. It is likely that this is reflective of the shift of potassium from the intracellular to the extracellular pools due to the severity of the metabolic acidemia. However, it is not known if changes in intracellular potassium have any effect on the fetal release of AVP.

Although the rise in plasma concentrations of AVP correlated with the decrease in arterial $\mathrm{pH}$ and changes in plasma osmolality did not occur or had no apparent effect, the levels of plasma AVP fell immediately after stopping the $\mathrm{NH}_{4} \mathrm{Cl}$ infusion, returning to preinfusion values at a time when significant metabolic acidemia persisted, i.e. a pHa of $7.12 \pm 0.03$. Moreover, although the acidosis persisted for up to $24 \mathrm{~h}$, plasma AVP concentrations remained at preinfusion levels. This would infer that either the threshold for AVP release by metabolic acidosis is around $\mathrm{pH}$ 7.00 or that the relationship of plasma AVP to arterial $\mathrm{pH}$ is superfluous. It is unlikely to be the former since plasma AVP concentrations gradually rose during the $\mathrm{NH}_{4} \mathrm{Cl}$ infusions, with significant increases occurring when the $\mathrm{pHa}$ was $\sim 7.20$ (Fig. 1), and there was a positive correlation between the rise in AVP and the fall in pHa. Thus, it appears that the increase in fetal AVP secretion is probably reflective of the exposure of the fetus to $\mathrm{NH}_{4} \mathrm{Cl}$ and that metabolic acidosis, as induced in the present paradigm, actually had little or no effect. Our results are in sharp contrast with those of Wang et al. (28) who observed in anesthetized adult dogs a 20 -fold rise in plasma AVP concentrations following hydrochloric acid infusions that decreased the arterial $\mathrm{pH}$ from 7.38 to 7.05. Nevertheless, since these changes in arterial $\mathrm{pH}$ were comparable to those obtained during induced hypercapnia, where AVP release was considered mild ( $\sim 3$-fold), these investigators suggested that factors other than the simple increase 
in the concentration of hydrogen ion in blood influenced the magnitude of the increase in plasma AVP seen with $\mathrm{HCl}(28)$. Our findings in unanesthetized fetal sheep support this hypothesis. However, the differences in AVP secretion in the adult and fetus could also reflect developmental (or species) differences, suggesting that the adult animal may be more vulnerable to metabolic acidosis.

As observed by Sklar and Schrier (1), a pitfall in the study of AVP release is the use of peripheral routes to administer agents, i.e. the agent, even if capable of crossing the blood-brain barrier, might exert its effect on AVP release via some alteration in the cardiovascular system and/or baroreceptor activity rather than by any direct central action. In our studies of fetal sheep there is nothing to suggest a peripheral effect through alterations in either baroreceptor or chemoreceptor activity, or changes in the cardiovascular system. There was no change in arterial $\mathrm{PCO}_{2}$, and $\mathrm{PO}_{2}$ was observed to rise. This tendency for arterial $\mathrm{PO}_{2}$ to increase is probably reflective of the effects of the metabolic acidemia on the oxygen dissociation curve, i.e. the Bohr effect (29).

Although levels of plasma catecholamines tended to rise during the infusion of $\mathrm{NH}_{4} \mathrm{Cl}$, we found no statistically significant increase in either D or NE. However, plasma concentrations of $\mathrm{E}$ did increase significantly near the end of the $\mathrm{NH}_{4} \mathrm{Cl}$ infusions. Moreover, there were no significant correlations between the fall in fetal arterial $\mathrm{pH}$ and the rise in plasma concentrations of these catecholamines. Thus, it appears that, as with AVP, pure metabolic acidosis induced by $\mathrm{NH}_{4} \mathrm{Cl}$ is not a potent stimulus to the release of catecholamines from fetal chromaffin tissue in nearterm fetal sheep and that the response of the fetal sheep is quite variable. This contrasts sharply with that seen in fetal sheep during significant hypoxemic-asphyxic episodes (17). However, as recently discussed (30), measurements of plasma catecholamine concentrations have many shortcomings. There are not only rapid changes in influx, efflux, or both, but also potential differences which are dependent upon the sampling site. In our study, the descending aorta was sampled, permitting us to compare our results with those of Cohen et al. (17), but not with Lewis et al. (31) or Jones and Robinson (32), who obtained their blood samples from the fetal carotid artery. We did not address the balance between the influx and efflux of these hormones; thus, the high variability observed in this study and that of others $(17,31,32)$ may represent the important variability between the secretion and metabolism of these neurohormones. We also were unable to discern any clear relationship between the release of catecholamines in the fetus and the release of AVP in response to metabolic acidemia. Thus, the potential of this important relationship remains to be determined.

The delayed, yet consistent increase in fetal HR seen from 90 min to $4 \mathrm{~h}$ following the $\mathrm{NH}_{4} \mathrm{Cl}$ infusion is strikingly similar to the delay of $\mathrm{NH}_{4} \mathrm{Cl}$-induced increases in fetal breathing previously reported by Molteni et al. (33). In those studies, vigorous fetal respiratory activity was consistently observed 60 to $90 \mathrm{~min}$ after completion of the infusion of $\mathrm{NH}_{4} \mathrm{Cl}$. They suggested that the delay was an effect mediated by central $\mathrm{pH}$ receptors. They studied fetal sheep at the same period of gestation as we did, infused $\mathrm{NH}_{4} \mathrm{Cl}$ over 2-3 $\mathrm{h}$ at the same dose, and observed the arterial $\mathrm{pH}$ to decrease to a mean of 6.82 , a value similar to the 7.03 reported herein. We did not measure the fetal breathing pattern or the cerebrospinal fluid $\mathrm{pH}$; however, because of the similarity of our findings and the experimental paradigm with that of Molteni et al: (33), we suggest that there may be a relationship between the induction of fetal breathing and the increase in fetal $\mathrm{HR}$ that follows $\mathrm{NH}_{4} \mathrm{Cl}$-induced metabolic acidemia. The possibility of a central chemoreceptor component is of interest and warrants further investigation, especially since this could be important in the pathogenesis of intrauterine aspiration of meconium (25).

Thus, it appears from the results of our studies that metabolic acidosis independent from changes in $\mathrm{PCO}_{2}$ and $\mathrm{PO}_{2}$ has at best only a mild effect on the fetal secretion of AVP. Furthermore, it is possible that there is actually no direct effect of the rise in hydrogen ion concentration since plasma AVP concentrations were observed to fall to levels not different from control by 60 min after the $\mathrm{NH}_{4} \mathrm{Cl}$ infusion, while arterial $\mathrm{pH}$ remained substantially depressed. This, however, does not negate the possibility of important interactions between changes in $\mathrm{pH}$ and $\mathrm{PO}_{2}$ in the fetal release of AVP.

Acknowledgments. The authors thank Sonnya Coultrup, Jodie Roberts, and Nhu-Y Dong for excellent technical assistance and Dawn Bovell for valuable secretarial assistance.

\section{REFERENCES}

1. Sklar AH, Schrier RW 1983 Central nervous system mediators of vasopressin release. Physiol Rev 63:1243-1280

2. Hoppenstein JM, Miltenberger FW, Moran WH Jr 1968 The increase in blood levels of vasopressin in infants during birth and surgical procedures. Surg Gynecol Obstet 127:966-974

3. Chard T, Hudson CN, Edwards CRW, Boyd NRH 1971 Release of oxytocin and vasopressin by the human fetus during labour. Nature 234:352-354

4. Hadeed AJ, Leake RD, Weitzman RE, Fisher DA 1979 Possible mechanisms of high blood levels of vasopressin during the neonatal period. J Pediatr 94:805-808

5. DeVane GW, Porter JC 1980 An apparent stress-induced release of arginine vasopressin by human neonates. J Clin Endocrinol Metab 51:1412-1416

6. Pohjavuori M 1983 Obstetric determinants of plasma vasopressin concentrations and renin activity at birth. J Pediatr 103:966-968

7. Alexander DP, Britton HG, Forsling ML, Nixon DA, Ratcliffe JG 1971 The release of corticotrophin and vasopressin in the foetal sheep in response to haemorrhage. J Physiol 213:31P-32P

8. Alexander DP, Britton HG, Forsling ML, Nixon DA, Ratcliffe JG 1974 Pituitary and plasma concentrations of adrenocorticotrophin, growth hormone, vasopressin and oxytocin in fetal and maternal sheep during the latter half of gestation and the response to haemorrhage. Biol Neonate 24:206219

9. Rose JC, Morris M, Meis PJ 1981 Hemorrhage in newborn lambs: effects on arterial blood pressure, ACTH, cortisol, and vasopressin. Am J Physiol 240:E585-E590

10. Alexander DP, Forsling ML, Martin MJ, Nixon DA, Ratcliffe JG, Redstone D, Tunbridge D 1972 The effect of maternal hypoxia on fetal pituitary hormone release in the sheep. Biol Neonate 21:219-228

11. Daniel SS, Husain MK, Milliez J, Stark RI, Yeh MN, James LS 1978 Renal response of fetal lamb to complete occlusion of umbilical cord. Am J Obstet Gynecol 131:514-519

12. DeVane GW, Naden RP, Porter JC, Rosenfeld CR 1982 Mechanism of arginine vasopressin release in the sheep fetus. Pediatr Res 16:504-507

13. Rurak DW 1978 Plasma vasopressin levels during hypoxaemia and the cardiovascular effects of exogenous vasopressin in foetal and adult sheep. J Physiol 277:341-357

14. Stark RI, Daniel SS, Husain KM, James LS, Vande Wiele RL 1979 Arginine vasopressin during gestation and parturition in sheep fetus. Biol Neonate $35: 235-241$

15. Daniel SS, Stark RI, Zubrow AB, Fox HE, Husain MK, James LS 1983 Factors in the release of vasopressin by the hypoxic fetus. Endocrinology 113:16231628

16. Axelrod J, Reisine TD 1984 Stress hormones: their interaction and regulation. Science 224:452-459

17. Cohen WR, Piasecki GJ, Jackson BT 1982 Plasma catecholamines during hypoxemia in fetal lamb. Am J Physiol 243:R520-R525

18. Rosenfeld CR, Morriss FH Jr, Makowski EL, Meschia G, Battaglia FC 1974 Circulatory changes in the reproductive tissues of ewes during pregnancy. Gynecol Invest 5:252-268

19. Rosenfeld CR, Worley RJ, Milewich L, Gant NF Jr, Parker CR Jr 1980 Ovine fetoplacental sulfoconjugation and aromatization of dehydroepiandrosterone. Endocrinology 106:1971-1979

20. Gresham EL, Rankin JHG, Makowski EL, Meschia G, Battaglia FC 1972 An evaluation of fetal renal function in a chronic sheep preparation. $J$ Clin Invest 51:149-156

21. Robertson GL, Mahr EA, Athar S, Sinha T 1973 Development and clinical application of a new method for the radioimmunoassay of arginine vasopressin in human plasma. J Clin Invest 52:2340-2352

22. Skowsky WR, Rosenbloom AA, Fisher DA 1974 Radioimmunoassay measurement of arginine vasopressin in serum: development and application. $J$ Clin Endocrinol Metab 38:278-287

23. Weitzman RE, Fisher DA, Robillard J, Erenberg A, Kennedy R, Smith F 1978 Arginine vasopressin response to an osmotic stimulus in the fetal sheep. Pediatr Res 12:35-38

24. Ben-Jonathan N, Porter JC 1976 A sensitive radioenzymatic assay for dopamine, norepinephrine, and epinephrine in plasma and tissue. Endocrinology 98:1497-1507

25. Wiriyathian S, Porter JC, Naden RP, Rosenfeld CR 1983 Cardiovascular effects and clearance of arginine vasopressin in the fetal lamb. Am J Physiol 
245:E24-E31

26. Forsling ML; Ingram DL. Stanier MW 1980 Plasma antidiuretic hormone during hypoxia and anaesthesia in pigs. J Endocrinol 85:253-259

27. Sladck JR. McNeil TH, Khachatweizn H, Zimmerman EA 1979 Chemical neuroanatomy of monoamine-neuropeptide interactions in the hypothalamic magnocellular system. In: Yoshida S, Share L, Yagi K (eds) Antidiuretic Hormone. University Park Press, Baltimore, pp 1-17

28. Wang BC, Sundet WD, Goetz KL 1984 Vasopressin in plasma and cerebrospinal fluid of dogs during hypoxia or acidosis. Am J Physiol 247:E449E455

29. Lambertsen RJ 1980 Transport of oxygen, carbon dioxide, and inert gases by the blood. In: Mountcastle VB (ed) Medical Physiology. CV Mosby Co., St. Louis, pp 1721-1748

30. Cryer PE 1984 Catecholamines and metabolism: introduction. Am J Physiol 247:E1-E3

31. Lewis AB, Evans WN, Sischo W 1982 Plasma catecholamine responses to hypoxemia in fetal lambs. Biol Neonate 41:115-122

32. Jones CT, Robinson RO 1975 Plasma catecholamines in foetal and adult sheep. J Physiol 248:15-33

33. Molteni RA, Melmed MH, Sheldon RE, Jones MD, Meschia G 1980 Induction of fetal breathing by metabolic acidemia and its effect on blood flow to the respiratory muscles. Am J Obstet Gynecol 136:609-620 